\title{
Revitalização da indústria de defesa no Brasil: desafios e oportunidades para o arranjo produtivo em São Bernardo do Campo
}

\section{Brazilian's defense industry revitalization: challenges and opportunities to the productive arrangement in São Bernardo do Campo}

\author{
ISABEL CRISTINA DOS SANTOS* \\ VINICIUS DOMINGUES NUNES **
}

\section{RESUMO}

Esta pesquisa tem como objetivo identificar os desafios à revitalização da indústria de defesa nacional a partir da implantação do arranjo produtivo local de defesa de São Bernardo do Campo. Para tanto, optou-se por uma abordagem qualitativa, com caráter exploratório-descritivo. A coleta de dados baseou-se em: análise histórica e documental, o que permitiu descrever a constituição do setor e identificar o crescimento e o declínio do setor, bem como, objetivos e estratégias definidas para o arranjo produtivo de Defesa. Entrevistas estruturadas realizadas junto a uma amostra de sujeitos, atuantes no setor, complementam a coleta de dados e apoiam a análise sistematizada dos aspectos inerentes aos cenários, no setor, alguns dos quais derivados da experiência empírica dos entrevistados. Os resultados obtidos apontam a necessidade de estabelecer parceria com o Governo, que deverá lançar incentivos econômicos, tecnológicos e institucionais para que a revitalização da indústria, como uma alternativa econômica e social relevante para o Grande $A B C$, possa lograr sucesso.

* Universidade Municipal de São Caetano do Sul. Programa de Pós-Graduação em Administração da Universidade Municipal de S. Caetano do Sul, nas áreas temáticas relacionadas a Conhecimento, Inovação e Desenvolvimento. isa.santos.sjc@gmail.com .

* Universidade Municipal de São Caetano do Sul. Escola de Negócios, Relações Internacionais.vinicius.d.nunes@gmail.com . 
Portanto, conclui-se que a definição dos desafios da indústria de defesa e do APL de São Bernardo do Campo está relacionada ao apoio ou à ausência dele por parte do governo.

Palavras-chave: Arranjo Produtivo Local. Indústria de Defesa. Armamentos Pesados. Desafios e Oportunidades.

\section{AbSTract}

This research aims to identify the challenges to the revitalization of the National Defense Industry from the implementation of local productive arrangement of São Bernardo do Campo's defense. To this end, we opted for a qualitative approach, with exploratory-descriptive character. Data collection was based on documentary and historical analysis, which describe the sector and identify the growth and decline of the sector, as well as, goals and strategies for the production of Defense. Semi-structured interviews were conducted with a sample of subjects, industry-focused, in order to complement the data collection and support the analysis of the inherent aspects in the scenarios, some of which derived from the empirical experience of respondents. The results highlight the need to establish a partnership with Government should launch economic, technological and institutional incentives for the revival of the industry, as an alternative social and economic relevance to the greater ABC, can achieve success. Therefore, it is concluded that the definition of the challenges from the defense industry and APL de São Bernardo do Campo are related to support or the lack of it on the part of the Government.

Key-words: Local Productive Arrangement. National Defense Industry. Heavy Weapons. Challenges and Opportunities.

\section{INTRODUÇÃo}

A indústria de defesa brasileira foi configurada nos anos de 1960, alcançou o seu auge em meados da década seguinte e vigorou até o início da década de 1990. Nesse período, três empresas nacionais destacaram-se pelo volume de produção interna e exportações. Foram elas: Engesa (Engenheiros Especializados S/A), fabricante de veículos blindados, Avibras, fabricante do sistema de artilharia de foguetes "Astros II", e Embraer - Empresa Brasileira de Aeronáutica, fabricante de aeronaves civis e militares. O fim da Guerra Fria definiria o declínio da indústria bélica em nível mundial. 
O declínio do setor, no início da década de 1990, pode ser explicado pelo fim do modelo lógico original da guerra, em razão das novas estratégias e tecnologias, tornando obsoletos os recursos e o modelo de ação vigente (STRACHMAN, DEGL'LILESPOSTI, 2010). Os reflexos da mudança e da redução do uso de equipamentos bélicos pesados foram percebidos no país e uma crise no setor foi instaurada. A falência da Engesa, a privatização da Embraer e a dura recuperação da Avibras são decorrências da crise e da opção do governo em importar equipamentos de defesa (LADEIRA JR, 2013). Das empresas citadas, a Embraer, nascida global, sustentou sua recuperação focada na aviação civil (SANTOS, AMATO NETO, 2005). Porém, decisões recentes do governo definiram a região do Grande $\mathrm{ABC}$ como lócus de revitalização da indústria da defesa, cuja relevância estratégica é apontada no Livro Azul de Ciência e Tecnologia (BRASIL, 2010).

O objeto debatido, neste estudo, é o setor da indústria responsável pela produção dos "grandes armamentos convencionais", que englobam aeronaves, veículos blindados, artilharia, sensores, sistemas de defesa aérea, mísseis, navios, motores e outros (MORAES, 2012). Sendo assim, estão exclusas as indústrias produtoras de armas e munições, assim como veículos e outros artefatos, que possam ser usados por forças policiais ou consumidas pelo mercado civil.

O objetivo principal é identificar os desafios do setor de defesa ao desenvolvimento do arranjo produtivo local de São Bernardo do Campo. Para tanto, foram desenhados objetivos secundários, que permitiram: identificar as categorias de análise, a partir do acervo bibliográfico e documental; elaborar os instrumentos de campo, identificar uma estrutura de análise para estimar os desafios, de acordo com a visão dos atores.

Este artigo está apresentado em cinco partes. A primeira apresenta o contexto em que se situa o objeto de estudo; na segunda parte são oferecidos os fundamentos que embasarão a contribuição teórica às escolhas metodológicas, que é descrita na terceira parte e orienta a elaboração do roteiro de entrevistas. Na quarta seção, são apresentados os resultados, e na quinta as considerações finais desta pesquisa e indicações de oportunidades para avanços futuros no debate. 


\section{FUNDAMENTOS TEÓRICOS}

O Brasil é o maior país da América Latina, e o quinto maior do mundo, com uma área de 8,515 milhões de quilômetros quadrados (IBGE, 2013), fazendo fronteira a oeste, com exceção do Chile e do Equador, com dez países da América do Sul e, a leste e nordeste, com o Oceano Atlântico, além das 200 milhas. A localização do país, na parte sul do continente americano, indica que a proteção das fronteiras é uma prioridade para o país. Ou deveria ser.

O Brasil possui 16.886 quilômetros de fronteiras com dez países, ao longo de 11 estados e 588 municípios. Os diversos problemas constatados na região, como contrabando, tráfico de drogas e de armas, roubo de cargas e de veículos e crimes ambientais, adquirem maior importância diante da insuficiência de monitoramento e de proteção bem evidentes (DEFESANET, 2011, s/p).

Dada a sua extensão, o país também tem os maiores gastos militares e também possui supremacia no total de forças armadas e no seu contingente. Tal fato leva à compreensão de que o Brasil é uma força militar dominante em sua região. Apesar disso, o país não oferece ameaça potencial aos países vizinhos. A solução diplomática tem sido a estratégia adotada pelo país, e interesses comerciais mútuos induzem a possibilidade de guerra ao nível mais remoto (ROCHA, 2012). A ofensiva mais recente do país na região data de 1870 .

\subsection{O Panorama Histórico do Setor de Defesa no País e no Mundo}

Embora existente no país de forma rudimentar, desde os tempos do Brasil colonial, a indústria de Defesa no país alcançou sucesso entre a década de 1970 até o início da década de 1990. Nessa década, a crise no setor de armamentos culminaria na falência da Engesa, na crise financeira na Avibras e econômica na Embraer fato que, na última, resultou na sua privatização e recuperação após poucos anos (SCHMIDT, ASSIS, 2013). Naquele período, a nacionalização tecnológica era uma meta em construção, para a qual contribuía a existência das melhores escolas de engenharia. 
Até a década de 1930, a indústria de defesa brasileira produzia mediante licença ou com tecnologia desenvolvida por outro país. Os artefatos de defesa de uso militar, no Brasil, como canhões, metralhadoras e viaturas blindadas eram adquiridos dos fornecedores estrangeiros, uma vez que o Brasil ainda não dispunha de um setor siderúrgico apto ao fornecimento do aço para fins de armamento, o que aconteceria somente na década de 1940 (AMARANTE, 2004; SANTOS, AMATO NETO, 2005), com a intervenção dos Estados Unidos no financiamento da indústria do aço, pois tinham interesse no aço brasileiro para o atendimento das demandas, primeiramente, da guerra e, depois dela, da reconstrução dos países mutilados e dos centros industriais europeus.

Nacionalmente, a criação da indústria siderúrgica era indispensável para "promover o reaparelhamento das Forças Armadas e a implementação de um vasto programa de obras públicas" (FGV CPDOC, 2017). A infraestrutura para apoiar a industrialização do país estaria lançada.

Santos e Amato Neto (2005) destacam como os acordos decorrentes da Segunda Guerra Mundial definiram, em grande medida, o curso da industrialização brasileira, na direção tanto na percepção da fragilidade do aparato de Defesa Nacional, quanto na limitada capacidade da indústria nacional em produzir produtos de conteúdo tecnológico. A indústria de aviação foi escolhida para inaugurar a trajetória da indústria tecnológica nacional e, com ela, os planos para desenvolver recursos humanos de alta qualidade em um ambiente de ensino apoiado por laboratórios de práticas. Assim, foram criados o Centro Técnico Aeroespacial (CTA) da Força Aérea Brasileira, atualmente denominado Departamento de Ciência e Tecnologia Aeroespacial; o Instituto de Pesquisas da Marinha para a Força Naval; e o Centro Tecnológico do Exército para a Força Terrestre (AMARANTE, 2004).

A ascensão do regime militar brasileiro na década de 1960, destarte a natureza do seu ingresso, favoreceu o contexto industrial brasileiro. Contribuições como o Programa de Ação Econômica do Governo (PAEG), durante a gestão de Castello Branco (1964-1967), e o Plano Brasil Grande Potência, do governo Médici (1969-1974), sobretudo, nas exportações, como aponta Vaz (p. 634-5). 
No que concerne à indústria, a aposta no aumento das exportações seria baseada em programas de incentivos à normalização (sistemas, produtos e processos oriundos de normas internacionais de uniformização e harmonização da produção industrial) e à qualidade (iniciativas relacionadas ao controle e gestão da produção com foco na melhoria contínua dos produtos e processos), alicerçados na metrologia.

Neste ponto, ressalta a revisão do setor de defesa brasileiro moderna. Todo o setor fundamentalmente tomou forma por meio de fatores políticos e econômicos que o governo militar prezava como parte de sua filosofia. Redução da dependência tecnológica estrangeira era um dos alvos (FONSECA, 2000).

A organização do setor visou atender a algumas finalidades. A primeira está relacionada à segurança nacional, assuntos relacionados ao poderio militar e suas capacidades de ataque e defesa em prol do país, assunto considerado vital no cenário da Guerra Fria em questão. O segundo motivo remete ao desejo do governo militar brasileiro, assim uma contribuição lógica do "Brasil Potência". E por fim, o terceiro motivo, promover a industrialização brasileira, em geral, incluindo a indústria bélica. $O$ investimento na indústria bélica pode ser examinado nos volumes exportados: Na década de 1980, os materiais bélicos saltaram de US\$ 17,8 bilhões de dólares, ao longo da década de 1970, para US $\$ 48,5$ bilhões de dólares (MORAES, 2012). E, nessa década, o Brasil foi o 11‥ maior exportador de material bélico do mundo (STRACHMAN, DEGL'LESPOSTI, 2010).

Ao longo da intensa atividade comercial e tecnológica norte-americana, marcadamente no pós-guerra, instalou-se um conflito ideológico entre os Estados Unidos e a União Soviética, mundialmente conhecida como Guerra Fria, que foi responsável por uma nova lógica militar que aceleraria a corrida armamentista entre as duas superpotências e induziria o mundo a um estado de vigilância contínua, pois o conflito era uma possibilidade constante (GADDIS, 2006). A ameaça comunista, cuja ideologia espalha-se pelos países das América Central e do Sul, criara o ambiente perfeito para intervenções militares ao sul do continente. Os ares do planeta no pós-guerra remetiam a conflitos localizados e o poderio nuclear já mostrara a sua face. A conquista de novos territórios deveria exibir 
o poder da tecnologia e o espaço seria a última fronteira para isso.

A queda da União Soviética, em 1991, significou o fim da Guerra Fria, fazendo que a necessidade de militarização se alterasse. Os volumes de exportação de produtos bélicos caíram em todo o mundo e a mudança de foco geográfico diante das novas ameaças, como a Coreia do Norte e Oriente Médio, por exemplo, reorientou a indústria (STRACHMAN, DEGL'LESPOSTI, 2010).

No Brasil, a exemplo da indústria mundial de armamentos pesados, foi um período de crise. A oferta gerada pelo setor bélico brasileiro estava acima da demanda de mercado. Ao mesmo tempo, a demanda enfraquecia devido à mudança mundial e aos estoques bélicos já sobrecarregados por todo o período do conflito ideológico de superpotências (STRACHMAN, DEGL'LESPOSTI, 2010). Com o fim da Guerra Fria, o país avançava na restauração da democracia, após duas décadas de governo militar e, por conseguinte, o fomento financeiro ao setor de defesa também reduziu, ao que parecia à época, o setor, que experimentava volumes crescentes de exportações, seria autossuficiente para gerenciar a sua atividade. O governo suspendeu o apoio financeiro, e político, às empresas do setor, o que repercutiria, anos depois, na sua sobrevivência (MORAES, 2012).

A queda no comércio mundial de armamentos militares está vinculada a três fatores exógenos básicos. Os países que eram potencialmente compradores diminuíram os recursos destinados a gastos militares. O padrão de compra de artefatos bélicos desses países mudou para a compra de serviços de manutenção e de atualização tecnológica dos arsenais já constituídos (STRACHMAN, DEGL'LESPOSTI, 2010). Outro fator foi a substituição das importações desses países compradores de tecnologia militar avançada pela estratégia de desenvolverem localmente a indústria de defesa. E o terceiro fator foi a preferência dos países compradores em manter o foco na importação de armamentos ultrapassados, o que ofereceria menor custo e maior confiabilidade

Como resultado da contenção do comércio oficial de armamentos pesado, as três maiores indústrias do setor de defesa brasileiro, a Engesa (fabricante de veículos de reconhecimento de combate), a Avibras (fabricante de mísseis, foguetes e plataformas de lançamento) e a Embraer (indústria do ramo aeronáutico) foram atingidas de 
forma brusca pela crise internacional do setor nos primeiros anos da década de 1990. Especificamente em 1994, as exportações brasileiras de armamentos atingiram seu menor valor desde o meio da década de 1980, que exibiu o auge do setor.

\subsection{Diretrizes da Defesa Nacional}

Desde a estabilização da moeda, final da década de 1990, o governo brasileiro tem tentado construir a imagem de potência emergente, desejando obter mais influência em organismos internacionais e uma postura mais participativa em decisões político-militares ao redor do mundo (CONCEIÇÃO, 2014), o que esbarra na publicidade negativa gerada por escândalos de corrupção e nos índices da violência. Mas, ao mesmo tempo, descobertas importantes no campo das riquezas minerais, como o petróleo nas camadas de pré-sal, a oferta de água potável, e ambientes inexplorados como a floresta amazônica, chamaram a atenção do mundo, indicando acervos que o país tem por obrigação proteger, justificando a necessidade de reaparelhamento e fortalecimento das Forças Armadas.

Tanto o Livro Branco de Defesa Nacional (BRASIL, 2012), quanto o Livro Azul e a Estratégia Nacional de Ciência, Tecnologia e Inovação para 2016 a 2019 (BRASIL, 2016), reforçam a Defesa Nacional como uma área prioritária à proteção do Estado brasileiro, e dos recursos naturais, território e da sociedade brasileira. Assim, reafirma-se o papel do Estado em garantir não só a soberania nacional, mas se manter preparado para o enfrentamento das pressões políticas ou outras formas de coerção internacional, ameaças externas, potenciais ou já manifestadas, que o impeçam de caminhar rumo ao próprio desenvolvimento de forma livre. Nos fundamentos da defesa nacional estão não somente a integridade do país como Estado-Nação, representada pelas noções principais de soberania e território como também a proteção de seus interesses políticos, e que se traduz pela necessidade de garantir a capacidade relativa do país em poder sobressair-se tanto quanto destacar-se no mundo, como apontou Conceição (2014).

As metas que apresentam um caráter construtivo, que remete ao fortalecimento das forças armadas brasileiras, ao desenvolvimento tecnológico necessário para que tais forças possam cumprir suas 
funções, e a capacidade de produção autônoma, que o país almeja, são os pilares para a continuação de todo o plano de defesa nacional (RUDZIT, 2014). Portanto, as metas presentes no Livro Branco de Defesa (BRASIL, 2012), reforçada pela Estratégia Nacional de Ciência, Tecnologia e Inovação (BRASIL, 2016), estão diretamente relacionadas à reativação da indústria bélica nacional e o desejo de seu desenvolvimento.

\subsection{A Retomada da Indústria}

Documentos da Prefeitura de São Bernardo do Campo destacam a meta de desenvolvimento econômico com base na indústria de defesa. De fato, a administração do governo municipal de São Bernardo do Campo acredita na intensa vocação da cidade e do Grande ABC paulista para a inovação nos segmentos da economia, sociedade e gestão pública (SÃO BERNARDO DO CAMPO, 2011). A importância e capacidades obtidas pela região são expressas como provenientes do parque produtivo preexistente, as lideranças empresariais que as controlam, a força de trabalho e a forte presença das forças sindicais instaladas no ABC.

A estratégia adotada pelo governo municipal, operada e desenvolvida pela gestão presente desde o ano de 2008, é calcada em três diretrizes básicas: a) manter e fortalecer a expertise desenvolvida na indústria automotiva e metalomecânica, que trespassa os limites de São Bernardo do Campo e existe em outras cidades do Grande ABC; b) explorar possibilidades propiciadas pelos investimentos na área de petróleo e gás; c) atrair investimentos relacionados à indústria de defesa, aproveitando as oportunidades de transbordamento tecnológico das indústrias e instituições existentes na cidade e na região (SÃO BERNARDO DO CAMPO, 2011).

$\mathrm{Na}$ terceira diretriz do desenvolvimento, a ideia do arranjo produtivo local de defesa obteve sua gênese, porém, de modo complementar à especialização regional no setor automotivo. Comparativamente aos setores já tradicionais da economia local, a indústria da defesa apresenta originalmente um caráter mais auspicioso. Inicialmente diferenciando-se do mercado civil, em que as decisões de compra e venda são tomadas por empresas e consumidores, a indústria de defesa tem como único comprador o Estado. E para esse 
mercado a aquisição de equipamentos, veículos ou armamentos é proveniente de um processo complexo de análise que envolve desde a tomada de decisão sobre quais produtos atendem às demandas específicas do uso no país - rapidamente, aviões de combate; informação/vigilância; transporte e apoio logístico; busca e salvamento; de treinamento - e setor de destino, qual seja, aviação naval ou aviação militar, até as especificações técnicas e tecnológicas dos produtos, até o processo de negociação, que envolvem governos e empresas fabricantes. O objetivo é, em geral, a parceria estratégica e, mais importante, a transferência tecnológica, que constituirão o modelo de manufatura.

A criação do arranjo produtivo local de defesa de São Bernardo do Campo não ocorreu de forma aleatória, tampouco sem planejamento. Segundo documento oficial, "Ações da prefeitura de São Bernardo do Campo para a área da Indústria de Defesa e Segurança", emitido pela Prefeitura do Município de São Bernardo do Campo, especificamente pela Secretaria de Desenvolvimento Econômico, Trabalho e Turismo, apresentado na conferência “O Comando da Aeronáutica apresenta seus Projetos e Demandas às empresas do ABC", realizada em julho de 2014, a indústria bélica nacional (referida em diversos momentos como "indústria de defesa e segurança"), é uma área em que o governo prevê uma extensa expansão para os próximos anos (SÃO BERNARDO DO CAMPO, 2011).

Para tal crescimento, a constituição do arranjo produtivo local (APL) de São Bernardo do Campo e, por proximidade, de interesse dos demais municípios do Grande $\mathrm{ABC}$, apresenta uma conveniente e importante compatibilidade: a localização; próxima ao porto e das principais vias de acesso aos centros econômicos e da principal fábrica de aviões no país; a preexistência do polo automotivo, que articulou a formação de mão de obra técnica capacitada; o número de instituições de ensino superior, sobretudo, no campo das engenharias, responsável pela mão de obra qualificada, que são fatores de produção facilitadores do desenvolvimento do APL.

A ideia de realizar o reaparelhamento das Forças Armadas, no âmbito da Política Nacional de Defesa, e o desenvolvimento da Base Industrial de Defesa no País, em consonância com a Estratégia Nacional de Defesa, depende de expressivos investimentos por par- 
te do Estado, prevendo montantes grandiosos advindos do Banco Nacional de Desenvolvimento Econômico e Social - BNDES - e a FINEP na área (SÃO BERNARDO DO CAMPO, 2011). Espera-se que os investimentos possam, gradualmente, gerar desenvolvimento socioeconômico local.

\subsection{Intersecções entre as Indústrias de Defesa e Civil}

O setor de defesa brasileiro foi objeto de estudos acadêmicos, principalmente no fim da década de 1970. Tais estudos abordavam duas vertentes: a primeira baseava-se no entendimento da indústria bélica na dimensão econômica, tal qual seria possível estudar outros ramos empresariais, que não o bélico; e a segunda vertente pesquisava a existência do transferimento de tecnologia do setor de defesa para outros ramos industriais da sociedade civil por meio do spin-off (FONSECA, 2000).

O conceito de spin-off está calcado na suposição de que a tecnologia empregada na indústria de equipamentos de defesa possa ter sua utilidade revertida para a sociedade civil. É possível notar que, desde a Segunda Guerra, período em que a pesquisa e o desenvolvimento foram altamente empregadas para a indústria de defesa e, mesmo com o direcionamento militar, apresentou suas utilidades para a indústria civil (DAGNINO, 2008).

Na prática, de acordo com o divulgado pela agência FAPESP (VASCONCELOS, 2015, p. 17), o spin off, seja de origem acadêmica ou industrial, posiciona como o "segundo maior mercado global de aviões experimentais, só superado pelos Estados Unidos". Algumas experiências bem-sucedidas no setor da aviação vêm sendo obtidas a partir da formação na carreira aeronáutica, desde o Instituto Tecnológico de Aeronáutica (ITA), de São José dos Campos, Universidade Federal de Minas Gerais; Escola de Engenharia de São Carlos da Universidade de São Paulo (EESC-USP) e por profissionais do setor e por inventores aficionados pela aviação. No setor militar, porém, a aviação passa necessariamente pelo crivo do governo, incluindo o estímulo às feiras de empreendedorismo aeronáutico e à inovação no setor, como o Simpósio de Transporte Aéreo, organizado pela Sociedade Brasileira de Pesquisa em Transporte Aéreo (SBTA), que reúne ex-alunos do ITA, civis e militares. 
O caso da Segunda Guerra Mundial pode ser analisado como um caso de spin-off intrafirmas, em que empresas do ramo civil foram convertidas para o esforço militar na empreitada aliada, conforme o caso norte-Americano e, após a conversão militarizada, os recursos bélicos desenvolvidos puderam ser reaproveitados para o desenvolvimento de outros produtos de destino civil, uma vez que as empresas foram reconvertidas ao seu propósito original (DAGNINO, 2008). Os casos de spin-off do ramo militar para a sociedade civil mostram-se decorrentes da proximidade do P\&D militar com determinadas áreas economicamente lucrativas das empresas civis que poderiam usufruir da tecnologia primordialmente imaginada para o uso bélico (FONSECA, 2000).

Um dado histórico de transferência tecnológica do setor bélico para o setor da indústria de aviação no Brasil refere-se ao trade off entre a diplomacia norte-americana e brasileira que, rompeu a sua neutralidade no conflito da Segunda Guerra Mundial ao aliar-se às forças militares norte-americanas e, em contrapartida, garantiu o suprimento de equipamentos para o seu arsenal bélico em formação e financiamento para a criação da Companhia Siderúrgica Nacional, eliminando o risco de apoio semelhante oferecido pela Alemanha (SANTOS, 2005; FERRAZ, 2005).

Podem ser citados, entre os produtos militares que tiveram sua tecnologia repassada pelo spin-off intrafirmas, as turbinas e cabines pressurizadas de aviões a jato, dispositivos de comunicação e detecção, semicondutores, computadores e outros que puderam ser adaptados para a aplicação comercial civil. Como um dado geral, não apenas empresas que foram convertidas para o esforço de guerra tiveram a oportunidade do spin-off; as colaborações entre empresas, contratações e outras interações fizeram que empresas diferenciadas, e que tivessem contato com o P\&D militar, pudessem aproveitar do fenômeno do spin-off. Essa característica está expressa por Dagnino (2008) como marcante para a recuperação e expansão da economia no pós-guerra.

Constata-se que as tecnologias de uso militar possuíam relativos benefícios, se comparadas com as de uso civil. Porém, foram empregadas efetivamente pela sociedade, gerando, dessa forma, as vantagens sociais e econômicas existentes, apenas com a quebra da barreira entre o emprego militar e o civil (DAGNINO, 2008). 
Nos anos de 1980, foi proposta uma lógica geral para o processo de spin-off que Fonseca (2000) descreve em cinco passos:

- O primeiro explica que os militares possuiriam uma demanda altamente exigente quanto à eficácia de seus equipamentos, portanto, apenas esforços em P\&D focados em áreas de ponta seriam utilizados para a constituição dos produtos. É exemplificado pelo autor que, no caso dos Estados Unidos da América, esse fenômeno aconteceria principalmente em megacorporações que tivessem divisões para produtos de natureza militar.

- O segundo explana que os produtos bélicos, já criados teoricamente em uma exigente tecnologia de ponta, teriam sua tecnologia mantida pelas corporações e os conhecimentos de sua confecção seriam difundidos para outras áreas que trabalham com o mercado civil. Sendo assim, aconteceria uma absorção do conhecimento pelas linhas de produtos civis.

- O terceiro remete ao fato de que, no momento em que essas tecnologias já atingiram um maior ponto e inserção nas linhas de produtos do mercado civil, elas passariam a adaptar-se para atender aos requisitos e custos demandados por tal mercado, redefinindo, assim, novas pontas tecnológicas.

- O quarto mostra que os projetos bélicos seguintes tomam os antigos como patamar a serem ultrapassados e, portanto, têm como expectativa obter mais tecnologia refinada e melhores desempenhos e/ou novas funções. Esse ponto se conecta diretamente com o quinto passo.

- No quinto, o ciclo recomeça. As novas tecnologias serão absorvidas pela empresa e por seus setores de produtos civis e a rotatividade do spin-off se consolidaria.

O caso brasileiro apresenta determinadas diferenças quanto ao pensamento inicial que fundamentou a teorização acerca do spin-off por meio das cinco constatações. A questão de que as megacorporações seriam as responsáveis por repassar a tecnologia aprendida para outros setores de mesmo porte é contestada pelo fato de que veículos blindados produzidos para uso militar por empresas de médio porte tiveram alianças com empresas automobilísticas gran- 
des, como a Ford, General Motors e Volkswagen (FONSECA, 2000). $\mathrm{O}$ autor ainda caracteriza outra categoria de spin-off, ou vertente de pensamento, que menciona um ponto adequado ao caso brasileiro. Essa categoria diferente cita que o produto final bélico, antes de ser absorvido pela indústria civil, passa por um processo não mencionado previamente, o aproveitamento de insumos desenvolvidos por tecnologia estrangeira. Após essa apropriação do conhecimento estrangeiro, o produto final bélico poderia ser repassado para a indústria civil e, então, completar o spin-off.

Por conseguinte, é possível concluir que a tecnologia de defesa apresenta não apenas ganhos para a segurança do país, como também a disponibilidade de propiciar a evolução tecnológica de outras áreas que não contemplam necessariamente o mercado militar. Um exemplo mencionado por Fonseca (2000), que confirma essa ideia, é o caso do Simulador de Míssil Superfície-Superfície, que foi desenvolvido por Murilo Santos, do Exército Brasileiro. Esse simulador foi concebido a partir da necessidade de suprir requisitos operacionais técnicos. Sua função consiste em simular o disparo de armas antiveículos, sem que munição real seja usada contra alvos reais. No setor civil, esse projeto foi aplicado na simulação de voos de helicópteros, foguetes para lançamentos de satélites, ensaios de deslocamento, velocidade de metrôs, entre outros.

A indústria de defesa mostra, logo, as suas contribuições e possibilidades, em que a tecnologia derivada do P\&D pode ser aproveitada por diversos ramos da sociedade em formas criativas de adaptar projetos para novos usos.

\section{MATERIAIS E MÉtodos}

A abordagem é qualitativa, pois propicia examinar o valor, a subjetividade, entre o objeto e o seu ambiente. Além disso, ela permite a interpretação de fenômenos e a atribuição de significados (SILVA; MENEZES, 2005; VIEIRA; RIVERA, 2012). Trata-se de uma pesquisa descritiva, delineada por análise bibliográfica e documental e por entrevistas semiestruturadas.

As pesquisas de caráter descritivo apresentam em seu cerne o objetivo de descrever as características de determinada população ou fenômeno, ou mesmo estabelecer a relação entre variáveis (GIL, 2002). 
A presente pesquisa possui em sua gênese a propriedade descritiva necessária para caracterizar a indústria de defesa e delinear as relações entre tais empresas. O processo de revisão teórica propiciou o alinhamento de conceitos referentes à indústria de defesa brasileira, dando origem às categorias de análise apresentadas na Figura 1:

\section{Figura 1: Contribuições Teóricas e Categorias de Análise}

\section{Contribuições Teóricas}

O setor de produtos de defesa, devido a seu pilar básico de venda às Forças Armadas dos países, tem em suas estratégias, a intervenção do Estado e de suas políticas de defesa. (STRACHMAN e DEGL'LESPOSTI, 2010)

Na década de 1990, é possível contemplar a ação e a filosofia, que metaforicamente podem ser representados como o"emagrecimento do Estado". Este momento gerou a tendência de privatizações nas empresas brasileiras, até mesmo as que outrora foram de interesse estratégico ao governo nacional (COSTA E SOUZA-SANTOS, 2010).

A queda da União Soviética, em 1991, significou o fim da Guerra Fria, e por consequência de suas lógicas implícitas. Portanto, a necessidade ideológica da constante militarização se alterou, os índices de exportação de produtos bélicos caíram em todo o mundo e a mudança de foco geográfico diante das novas ameaças delimitou novos paradigmas (STRACHMAN e DEGL'LESPOSTI, 2010).

O conceito de spin-off é calcado na suposição de que a tecnologia empregada na indústria de equipamentos de defesa, possa ter sua utilidade revertida para a sociedade civil (FONSECA, 2000; DAGNINO, 2008).

[...] possibilidades de interações entre os centros regionais e os não geograficamente próximos, como também o intercâmbio tecnológico que ocorre entre as empresas e o conhecimento proveniente das pesquisas feitas na região, assim como tantas outras comunicações entre o potencial de pesquisa da cidade e a capacidade produtiva de suas empresas [...] (SOUZA; COSTA, 2012)

Recentemente, decisões do governo definiram a região do grande $A B C$ como lócus de revitalização da indústria da defesa, cuja relevância estratégica é apontada no Livro Azul de Ciência e Tecnologia (2010).
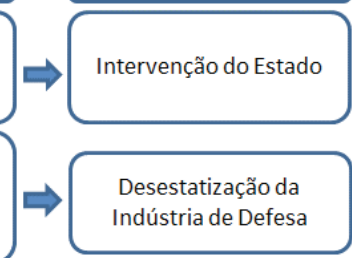

Fonte: Os autores

Como é possível observar, os pressupostos teóricos destacados são convertidos em categorias de análise. Essas categorias são a essência condensada e delimitada das observações teóricas, previamente dimensionadas em suas respectivas análises.

As categorias de análise contribuíram para a formulação de hipóteses, apresentadas na Figura 2, cuja verificação orientou as demais etapas dos procedimentos metodológicos. 


\section{Figura 2 - Hipóteses de Pesquisa}

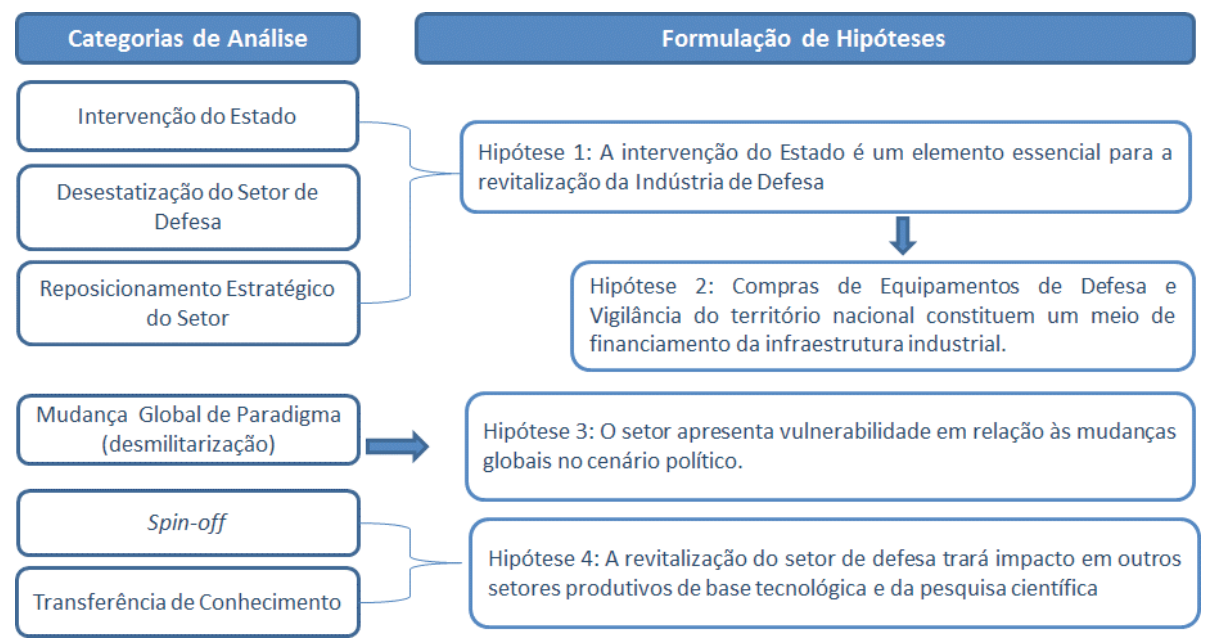

Fonte: Os autores

Cada hipótese gerou duas questões, no total de oito questões com as quais os atores, selecionados por acessibilidade, foram entrevistados, como exibe a Figura 3.

\section{Figura 3 - Questões Norteadoras}

1. Que tipo de apoio a indústria de defesa nacional poderá obter do governo como garantia de sucesso?

2. Como esse apoio governamental poderá ser uma fonte de vantagens competitivas duradouras do setor?

3. O APL de defesa de SBC tem o apoio do governo brasileiro, mas, na sua opinião, o mercado internacional oferece oportunidades para a expansão de suas atividades? Quais seriam essas oportunidades?

4. Quais riscos o APL de defesa de SBC corre em relação ao mercado-alvo (aviões-caça)?

5. Quais alterações no quadro político, nacional e internacional, podem comprometer o sucesso do APL de defesa em SBC?

6. Para quais ameaças da concorrência internacional, o APL de defesa de SBC deverá estar preparado?

7. Quais oportunidades, para as empresas de material de defesa, a revitalização do setor poderá gerar?

8. Quais oportunidades serão estabelecidas entre as empresas do APL de defesa de SBC com os Centros de Pesquisa Científica e as Instituições de Ensino Tecnológico Superior?

Fonte: Os autores

32 Organizações em contexto, São Bernardo do Campo, ISSNe 1982-8756 • Vol. 15, n. 29, jan.-jun. 2019 
Para estimar os desafios, ameaças e oportunidades do ambiente externo, e as forças e fraquezas da indústria, utilizou-se a Matriz SWOT.

A proposição desta dissertação a respeito das lições aprendidas no APL de São José dos Campos e nas suas respectivas empresas pode indicar os desafios que outro APL em região próxima, assim como em um mesmo setor, pode sofrer em seu período de criação, existência e possíveis crises. Portanto, tais informações têm o potencial de serem consideradas lições aprendidas passíveis de uso pelo novo APL.

Portanto, as informações obtidas na análise teórica são relacionadas aos pontos fortes, que são considerados vantajosos para as empresas do setor; aos pontos fracos, que representam questões frágeis do setor. Uma vez considerados esses pontos, é possível compreender quais podem ser compreendidos pelo APL de defesa de São Bernardo do Campo e possam servir como lição aprendida que o APL pode aproveitar ou se desviar para evitar maiores dificuldades.

\section{RESUltados}

O presente tópico tem como intenção apresentar as contribuições dos autores da revisão teórica para a pesquisa. Por meio dos autores mencionados, as estruturas teóricas da pesquisa puderam ser fundamentadas, e, somente a partir de tais alicerces, a convergência entre os recursos bibliográficos e os recursos práticos fornecidos pela análise documental pôde ser configurada.

Os resultados confirmam que a conjuntura política da Guerra Fria, assim como o governo militar do Brasil foram fatores cruciais para a consolidação do setor de defesa nacional. Mas, embora tenha sido condição essencial, não foi o suficiente para sustentar o modelo industrial altamente vulnerável às alterações políticas nacionais e internacionais que afetaram o desenvolvimento e a progressão da indústria de defesa nacional. A sustentabilidade econômica do setor, no Estado democrático, é um desafio.

A política neoliberal dos anos 1990 reduziu o número de instituições e atores públicos no setor. Essa estratégia solapou o poder da indústria de defesa, mesmo sendo ela vital para a estratégia de 
defesa do país, fragilizando o setor que, como um todo, demanda apoio do Governo para a sua sobrevivência.

Há reconhecimento do efeito spin-off da indústria de defesa para a produção civil, resultando em produtos de alta tecnologia. Com isso, o setor é visto como fonte de crescimento e desenvolvimento tecnológico e econômico. Sua revitalização constitui uma oportunidade para o setor, propiciando intercâmbio de conhecimentos da indústria com centros de pesquisa e com instituições de ensino focadas na tecnologia e na formação de recursos humanos qualificados.

A composição da obra de Strachman e Degl'lesposti (2010) apresenta inicialmente a ideia de que o Estado é uma entidade cuja participação é fundamental para a indústria de defesa do Brasil. Dentro de sua análise histórica é abordado o conceito de que a conjuntura política da Guerra Fria, assim como o governo militar do Brasil foram fatores determinantes para a consolidação de todo o setor de defesa nacional durante o século XX.

Portanto, a análise histórica feita pelos autores relata a importância do Estado para o setor, assim como a vulnerabilidade diante de alterações políticas nacionais e internacionais que podem afetar o desenvolvimento e a progressão da indústria de defesa nacional.

Outros autores que também se valem da análise histórica em seus argumentos são Costa e Souza-Santos (2010), que destacam o fato de que o governo neoliberal dos anos 1990 funcionava sob a filosofia da diminuição de atores nacionais ligados diretamente ao Estado. Portanto, esse foi o momento das privatizações brasileiras e do afastamento governamental de diversos setores da indústria, mesmo a indústria de defesa sendo parte da estratégia de defesa do país.

A ligação entre Strachman e Degl'lesposti (2010) e Costa e Souza-Santos (2010), é a base fundamental da concepção da necessidade do envolvimento estatal na existência e sobrevivência do setor de defesa brasileiro.

Representando a comunicação entre a indústria de defesa brasileira e o mercado civil, Fonseca (2000) e Dagnino (2008) retratam o fenômeno de spin-off, o qual descreve a escalada do desenvolvimento tecnológico por meio das pesquisas para a produção de artigos de defesa. O conceito se explica no momento em que produtos inicial- 
mente planejados para o uso militar possuem tecnologias que outras empresas aproveitam para a configuração de artigos civis.

O spin-off é uma fonte de crescimento e desenvolvimento tecnológico, com capacidade de beneficiar diferentes parcelas populacionais, garantindo assim que a indústria de defesa seja necessária não somente para o abastecimento de seu mercado consumidor tradicional, como também a um mercado civil beneficiado indiretamente.

Uma vez que seja constatado por Fonseca (2000) e Dagnino (2008) que existe a conexão da indústria de defesa com outros setores da sociedade, coube nesta pesquisa a Souza e Costa (2012) mostrarem outro tipo de interação que há com relação às empresas do setor.

Souza e Costa (2012) descrevem o intercâmbio de conhecimentos que a indústria de defesa pode fazer com centros de pesquisa e desenvolvimento, assim como com instituições de ensino focadas na tecnologia e na formação de profissionais capacitados ao trabalho no setor. Essa conexão retrata a capacidade de buscar inovações em instituições existentes na região, para que assim ambos os envolvidos possam ter seus interesses desenvolvidos e supridos.

Os documentos e livros de origem governamental, tanto do governo federal como da prefeitura de São Bernardo do Campo, sintetizam os pensamentos dos autores mencionados, pois, a revitalização do setor, por meio de investimentos e do desenvolvimento do APL de defesa de São Bernardo do Campo, se baseia nos elementos citados. Os arquivos governamentais estudados descrevem a importância da relação entre o setor e o Estado, os riscos que podem ocorrer uma vez que o apoio governamental mude, seja diminuído ou eliminado. Ao mesmo tempo, descrevem a importância da indústria de defesa para a sociedade local, suas empresas de outros setores e as instituições de ensino e pesquisa que podem usufruir do intercâmbio de informações e tecnologia.

Portanto, os fatores que cada autor destaca são complementares e apoiaram esta pesquisa para a realização de seus objetivos com relação não somente à indústria de defesa brasileira, como também sua história, seus momentos de ascensão, queda e revitalização, além de demonstrar as conexões que existem entre as empresas do setor com o seu ambiente. 


\section{CONSIDERAÇõeS FINAIS}

A presente pesquisa permitiu examinar as condições atuais, riscos e oportunidades que o setor da indústria nacional de defesa enfrenta e para o qual deverá estar preparado, cuja APL de São Bernardo do Campo deve formar-se com características globais, em razão dos aportes tecnológicos e dos agentes que constituem a APL.

Com relação ao problema de pesquisa, que se trata da seguinte questão: quais são os desafios para o desenvolvimento do APL de defesa de São Bernardo do Campo? Tornou-se possível, por meio das pesquisas e dos dados coletados, constatar que o APL de defesa de São Bernardo do Campo tem desafios quanto à necessidade iminente do apoio e compras governamentais, assim como o desafio de se desenvolver em um ambiente político e econômico instável, que não apresenta credibilidade diante da necessidade clara de apoios fiscais, monetários e tecnológicos, o que se mostra importante diante de uma concorrência internacional forte e experiente.

As lições que foram aprendidas com a constituição desta pesquisa focam as condições, riscos e oportunidades no setor da indústria nacional de defesa. Encontrando na análise bibliográfica a fundamentação para as categorias de análise de intervenção do Estado, desestatização da indústria de defesa, mudança global de paradigmas políticos, que afetam o setor, o conceito de spin off e a forma que o segmento pode render tecnologia a setores civis, a transferência de conhecimentos que ocorrem de centros de pesquisa e universidades para as indústrias de defesa e o reposicionamento atual do setor, que se dá expressivamente por meio do APL de defesa de São Bernardo do Campo.

Juntamente às categorias que propiciaram o panorama do setor, aprendeu-se que a indústria de defesa brasileira e mais especificamente o APL de defesa de São Bernardo do Campo deve atentar para as fragilidades tecnológicas e políticas do Brasil, assim como de sua concorrência internacional. Contudo, conta com pontos positivos que fortalecem as possibilidades do sucesso de sua reestruturação, principalmente o apoio governamental, que se mostra vital para a existência do setor produtivo de defesa, por meio de compras feitas ao setor, ajustes tributários e incentivos que garantem o fortalecimento da indústria, como a criação de centros tecnológicos. 
As contribuições garantidas pela pesquisa são explicitadas no fato de que a pesquisa contribui para o entendimento do funcionamento da indústria nacional de defesa, assim como para a análise histórica do Brasil e do sistema internacional por meio da visão de um segmento industrial diferenciado do mercado comum.

Embora seja de reconhecimento que a pesquisa em uma aglomeração embrionária ofereça limitações ao estudo, é possível examiná-las como oportunidades de avanços em estudos futuros, pois as diferentes fases do desenvolvimento da indústria e os seus impactos sobre a localidade podem ser estudados ao longo do tempo e comparados com outros arranjos produtivos implantados no país.

\section{REFERÊNCIAS}

AMARANTE, J. A. do. As Forças Armadas e o desenvolvimento científico e tecnológico do País. Brasília: Ministério da Defesa, Secretaria de Estudos e Cooperação, 2004.

BRASIL. Ministério da Ciência e Tecnologia. Livro Azul de Ciência Tecnologia e Desenvolvimento Sustentável. Brasília: 2010.

BRASIL. Ministério da Defesa do Brasil. Livro Branco da Defesa Nacional. Brasília: 2012.

BRASIL. Ministério da Ciência, Tecnologia e Inovação. Estratégia Nacional de Ciência, Tecnologia e Inovação 2016-2019. Brasília: MCTI, 2016.

CONCEIÇÃO, J. J. da. O arranjo produtivo local de defesa do Grande ABC. Revista do APL de defesa do Grande ABC, v. 1, n.1, p. 42-7, 2014.

COSTA, A. D.; SOUZA-SANTOS, E. R. de. Embraer, história, desenvolvimento de tecnologia e a área de defesa. Economia \& Tecnologia, v. 22, 2010.

DAGNINO, R. Em que a economia de defesa pode ajudar nas decisões sobre a revitalização da Indústria de Defesa brasileira? Revista de economia heterodoxa, n. 9, 2008.

DEFESANET. SISFRON - Proteção das Fronteiras e a Indústria Nacional de Defesa - Informe COMDEFESA. Edição de 27/06/2011. Disponível em http://www.defesanet.com.br/terrestre/ noticia/1651/SISFRON. Acesso em 10/05/2017.

FERRAZ, F. C. A. Os Brasileiros e a Segunda Guerra Mundial. Rio de Janeiro: Jorge Zahar Ed., 2005.

FGV CPDOC. Centro de Pesquisa e Documentação de História Contemporânea do Brasil. CSN: uma decisão política. Disponível em: http://cpdoc.fgv.br/producao/dossies/FatosImagens/ CSN. Acesso em 24/03/2017.

FONSECA, J. W. F. O desenvolvimento da indústria bélica no Brasil e seu processo de Spin-Off. Revista da Economia Política, v. 20, n. 3, p. 136-51, 2000.

GADDIS, J. L. História da Guerra Fria. Rio de Janeiro: Nova Fronteira, 2006.

GIL, A. C. Como elaborar projetos de pesquisa, 4. ed. São Paulo: Atlas, 2002. 
IBGE. Instituto Brasileiro de Geografia e Estatística, 2013. Disponível em: http://brasilemsintese.ibge.gov.br/territorio/dados-geograficos. Acesso em: 4 de fevereiro de 2015.

LADEIRA JR, P. C. A ascensão e queda, e os desafios de crescimento das empresas de defesa Avibras e Engesa. Dissertação de Mestrado. Universidade Federal do Rio de Janeiro - Instituto COPPEAD, 2013. Disponível em: www.coppead.ufrj.br/upload/publicacoes/ Paulo Ladeira Junior.pdf . Acesso em 10/09/2016.

MORAES, R. F. A inserção externa da indústria brasileira de defesa: 1975-2010. Brasília: IPEA, 2012.

ROCHA, M. S. A base industrial de defesa brasileira: uma análise do período de 1970 a 2000. Porto Alegre: Revista Brasileira de Estudos de Defesa, 2012.

RUDZIT, G. "Todo o comércio de armas entre países é política per si”, 2014. Disponível em: http://jornalggn.com.br/noticia/\%E2\%80\%9Ctodo-o-comercio-de-armas-entre-paises-e-politica-per-si\%E2\%80\%9D. Acesso em 23/09/2014.

SANTOS, I. C.; AMATO NETO, J. Estratégias para criação da Indústria aeroespacial brasileira. G\&DR, 1(2), mai./ago. 2005.

SÃO BERNARDO DO CAMPO. Prefeitura Municipal. Grande ABC: nova fronteira da indústria de defesa. São Paulo: MP Editora, 2011.

Ações da prefeitura de São Bernardo do Campo para a área da indústria de defesa e segurança. São Bernardo do Campo, 2014.

SCHMIDT, F. H.; ASSIS, L. R. S. A dinâmica recente do setor de defesa no Brasil: análise das características e do envolvimento das firmas contratadas. Texto para discussão 1878. Instituto de Pesquisa Econômica Aplicada. Brasília: Rio de Janeiro: IPEA, 2013.

SILVA, E. L; MENEZES, E. M. Metodologia da Pesquisa e Elaboração de Dissertação. Florianópolis: UFSC, 2005.

SOUZA, A. A. M.; COSTA, W. M. Análise de uma tecnópole brasileira: o caso do complexo tecnológico-industrial-aeroespacial de São José dos Campos. Porto: Universidade do Porto, 2012.

STRACHMAN, E.; DEGL'LILESPOSTI, E. H. B. A indústria de defesa brasileira: o setor de carros de combate e a Engesa. Porto Alegre: Ensaios FEE, 2010, v. 31, n. 1.

VASCONCELlOS, Y. Berçário de Aviões. Revista Pesquisa FAPESP, ed. 234, agosto de 2015. Disponível em: http://revistapesquisa.fapesp.br/wp-content/uploads/2015/08/016-23 Avi\%C3\%B5es 234.pdf?a41a60. Acesso em 23/04/2017.

VIEIRA, A. M.; RIVERA, D. P. B. A Hermenêutica no Campo Organizacional: duas possibilidades interpretativistas de pesquisa. Revista Brasileira de Gestão de Negócios, v. 14, n. 44, p. 261-273, 2012.

Recebido em: 10-5-2017

Aprovado em: 30-08-2017

Avaliado pelo sistema double blind review.

Editor: Coordenação do PPGA/UMESP

Disponível em http://mjs.metodista.br/index.php/roc 